the same in copper conductors, whether it be urged by alterate or by steady currents.

Prof. G. Forbes, F.R.S., and Mr. W. H. Preece, F.R.S., in a paper on a new thermometric scale, suggest the joule as the thermal unit instead of the therm or the calorie. $4^{\prime} 2$ joules will raise the temperature of 1 gramme of water at $4^{\circ}$ one degree, hence to raise $I$ gramme of water from freezing-point to boilingpoint requires 420 joules; and it is suggested that the difference of temperature between freezing- and boiling-points should be represented by 420 units of temperature.

Mr. J. T. Bottomley, F. R.S., exhibited some large Leyden jars, broken during the testing of a large Wimshurst machine which was being constructed by Sir Archibald Campbell, Bart., of Blythswood. They were excellent examples of multiple fracture.

Prof. S. P. Thompson, in a paper on sparkless electro-mainets, discussed the various means of suppressing the sparks in the circuits of electro-magnets. The most effective means, he finds, is to surround the core of the magnet with a substantial shield of copper. The author illustrated his method by experiments before the Section.

Mr, W. W. Haldane Gee and Dr. Arthur Harden read a paper on stereometry. This communication relates to the methods used for the determination of the volumes of bodies to which the hydrostatic method is not applicable. The authors have devised a convenient form of instrument, first proposed by Say, and afterwards modified by Le.lie, Kopp, Regnault, and Miller. They have also shown that the following method for ascertaining volumes is very generally applicable, and likely to be of considerable service in physico-chemical researches. The body whose volume is desired is inclosed within a vessel of known volume, and then carbon dioxide (or other dry soluble gas) is passed into it for some time. The gas is then displaced by dry air (or other gas), and the volume of the carbon dioxide driven out is ascertained gravimetrically by absorption in bulbs containing caustic potash solution. By first filling the vessel with dry air and then driving it out with carbon dioxide, the volume of the air, and hence that of the body, may also be ascertained volumetricaly, but with less accuracy. The gravimetric method is especially applicable for accurately ascertaining the density of soluble gases. For this purpose it is far more convenient than the process of direct weighing as used by Regnault.

In a paper on the specific heat of caoutchouc, $\mathrm{Mr}$. W. W. Haldane Gee and Mr. Hubert L. Terry described a number of determinations which had been made of the specific heat of Para india-rubber which had teen masticated, hydraulically compressed, and then cut into sheets from 0.22 millimetre to I 40 millimetre thick. The rubber was alternated with sheets of tinfoil, and heated for two hours in a steam-jacket at $100^{\circ} \mathrm{C}$. A modification of Regnault's method of mixtures was employed to find the specific heat of the hot rubber. Owing to the non-conducting nature of the substance the time of the calorimeter attaining its maximum temperature is as long as ten minutes; hence it has been necessary to apply special formulæ for the correction due to cooling. Those proposed by Pfaundler, Pape, and Schuster have been used, and the results calculated in accordance with them. The mean of the best-conducted experiments gives for the Para rubber the number $0: 486$. The investigation is being extended to allied bodies, especially the different forms of vulcanized rubber and gutta-percha.

Mr. F. T. Trouton read a paper on the temporary thermocurrents in iron. If a portion of an iron wire connected up to a galvanometer be heated red hot, and the heated portion be caused to travel along the wire by moving the flame, a current is produced, which is due to the fact that when iron changes its molecular te at the temperature of recalescence this change does not tal.: place at the same temperature on heating as on cooling, so that when a flame is moved along an iron wire so as to continuously heat it above the temperature of recalescence the junction of the altered with the unaltered metal in front is at a higher temperature than of the junction behind the flame.

Prof. Barrett read a paper on recalescence of iron.

\section{THE CHEMICAL PAPERS AT THE BRITISH} ASSOCIATION.

WING, doubtless, to the numerous chemical industries of the district, many of the papers read in Section B at Newcastle were of special interest to the technical student.
The President's Address on "The Metallurgy of Iron" was followed by the kitcort of the Committee for Investigating the Influence of Silicon on the Properties of Steel. From the results of Mr. Hadfield's experiments, it appears that silicon by itself does not produce a steel that will harden by water-quenching. The brittleness noticed in ordinary so-called silicon steel is due, not to silicon alone, but to the combined presence of the two hardeners, silicon and carbon. Silicon, up to 6 per cent., does not destroy the malleability of iron, nor are the magnetic properties greally affected by increasing percentages of silicon, as is the case with manganese steel.

The Committee for Establishing an International Standard for the Analysis of Iron and Steel reported that they had made goed progress with the work, and hoped before long to have the necessary analyses completed.

Some curious experiments were described by Mr. J. W. Hogg, on the volatilisation of lead oxide and its action upon glass at low temperatures. If some writing is placed upon a glass plate or platirum-foil, using lead oxide as a pigment, if a polished plate of glass be placed over this as closely as jossible and prevented from actual centact by suitable means, upon now heating up to scarcely visible rednes, a distinct reverse of the design will appear upon the upper glass. 'The quantity of lead oxide which will produce this effect is not shown by the most delicate balance.

Photographers were interested in Prof. Liveing's account of a new developer, "Eikonogen," which appears to give greater detail than most of those now in use. The tone of the negative is also excellent. Eikonogen is the sodium salt of amido$\beta$-naphthol- $\beta$-sulphoric acid.

Mr. C. T. Heycocik and Mr. F. H. Neville read a paper on Raoult's method applied to alloys. Alloys of a number of metals with sodium and tin were studied. The "atomic fall" of the freezing-point for aluminium was about half that of most other metals-pointing to twice the present number as the atomic weight of aluminium. Antimony produces a rise in the freezing-point of the alloy, for some unexplained reason. Contrary to Raoult's so-called second law, it was found that the nature of the solvent is of influence; I atomic weight of metal in $r o 0$ atomic weights of sodium not giving the same fall as $I$ in 100 of tin. The method would seem to give a means for correcting and verifying atomic weights; though it does not give much information as to the molecular weight. It was shown that, in accordance with Van 't Hoff's theories on the nature of solution, each metal produces its own lowering of the freezing. point in presence of others.

On the Friday morning, Prof. Dunstan read the Report on the present methods of teaching chemistry.

Prof. Bedson afterwards gave an interesting description of Dr. Netto's process, at work on the Tyne, for the manufacture of aluminium from cryolite. The cryolite is first fused with salt in a reverberatory furnace; then run out into converters in which sodium is gradually added-about five pounds at a time. Sodium fluoride and metallic aluminium are formed. The sodium is obtained by allowing molten caustic soda to flow gradually onto charcoal contained in a cast-iron retort heated to clull redness. The sodium carbonate formed in the reaction sinls to the bottom of the retolt. The greater concentration of the caustic soda thus produced enables the temperature to be kept lower than in the Castner process.

An account was afterwards given, by Mr. J. H. I. Dagger, of the Cowles method for manufacturing aluminium alloys.

On Monday, numerous Reports of Committees were handed in, the most interesting being that read by Dr. Richardson on the action of light on the hydracids. Dr. Richardson has found that, if white light is allowed to act upon water in presence of oxygen, a considerable quantity of hydrogen percxide is productd. This accounts for the fact mentioned in previous Reports, that a mixture of dry oxygen with dry hydrogen chloride, or bromide, is unaffected by light.

Dr. Richardson also exhibited and described a new selfregistering actinometer, based on the fact, discovered by Budde, that chlorine expands in the actinic rays, contracting again in the dark.

Prof. H. B. Dixon gave an account of experiments made by himself and Mr. J. A. Harker, on the explosion of a mixture of hydrogen, chlorine, and oxygen. It was found, in contradiction to previous statements, that steam is produced by the explosion even when chlorine is in excess. It was noted that hydrogen and chlorine, when exploded alone, give a sensible contraction. 
In another paper the same workers show that hydrogen and chlorine do not explode when dry, unless exposed to very intense light.

Dr. A. P. Laurie gave some results of his researches on artists' colours. $\mathrm{He}$ is comparing the recipes given in the manuscripts of the old masters with those in modern use.

A. new ferment was described on Tuesday, in a paper by Prof. P. F. Frankland, Miss Grace F. Frankland, and Mr. J. J. Fox. From the products of its activity, ethyl alcohol and acetic acid, it is termed Bacillus ethaceticus. It will cause a solution of mannite to ferment, while dulcite is unaffected by it.

In his paper on the Constitution of the Aromatic Nucleus, $\mathrm{Mr}$. S. A. Sworn gave preference to the octahedral formula of Thomsen. A further development of Thomsen's formula, he believes, affords a full explanation of the laws of para- and meta-substitution.

I)r. Isaac Ashe read a paper entitled "Dimidium : an Attempt to represent the Chemical Elements by Physical Forms." He put forward the view that the primordial basis is to be found in an element having half the combining weight of hydrogen. This hypothetical element is named dimidium. The relations of attraction and repulsion under the influence of polar force suggest a linear form for such a body. A series of vortex-rings, superposed one on the other, would yield a form elongated in one direction and limited in the other two. Having shown that the primordial element may have a bar-like form of definite length, the author proceeds to construct models of the different elements, conforming in each case to the combining weight, valency, crystalline form, \&c.

\section{SOCIETIES AND ACADEMIES.}

PARIS.

Academy of Sciences, September 30.-M. Des Cloizeaux, President, in the chair.-Presentation of the fourth sheet of the Bulletin of the International Committee for preparation of a map of the heavens; meeting of Committee at Paris Observatory, by M. E. Mouchez. Five other Observatories (Vienna, Catania, Mexico, Manilla, and the Vatican) have been added to the original sixteen. Each Observatory will have to take about 700 photographs in the zone alloted to it, and it is hoped to finish the work in three or four years. A central office for utilizing the results will be necessary.-Addition to the theory of thin weirs extending throughout the breadth of the bed of a water-course ; calculation of variations in the contraction of the outflowing sheet at its lower face, by M. J. Boussinesq. On the last communication of Halphen to the Academy, by II. F. Brioschi.-On the denomination of the industrial unit of work, by M. H. Resal. He advocates the unit of roo kilogrammetres, to be called the quintalmutre.-On the application of high temperatures in observing the spectrum of hydrogen, by MM. L. Thomas and Ch. 'Trépied. The electric arc is found a sure and comparatively easy way of making hydrogen sufficiently lu ninous for spectroscopic observation, even with large dispersions; (four jets of the gas were made to converge conically towards an axis coinciding with that of the carbons). On concatenation (enchainement) of the atomic weights of the elements, by M. Delauney. He shows that the atomic weights may be joined together by addition in each case of the square root of a whole number, which is variable, but always harmonic (not containing any other prime factors than $1,2,3$, and 5). Combinations of cupric oxide with amylaceous matters, sugars, and mannites; new reagents for proximate analysis, by $M$. Ch.-Er. Guignet. Solutions of cellulose, also dry starch, or inuline, give well-defined combinations with oxide of copper, when put in contact with its solution in ammonia. Some sugars (pure slucose from honey, galactose, \&c.) quickly precipitate copper a nmonio-sulphate (but not the oxide); and while inverted sugar does not precipitate the sulphate, a previous addition of glucose produces a deposit of the glucosic combination (which doe not retain ammonia). Mannite and dulcite, \&c., yield at once blue precipitates in an ammoniacal sulphate of copper solution, which reagent is useful with decoctions of vegetable matters, as most substances in these are not precipitated by it.-On the number and calibre of nerve-fibres in the common oculomotor nerve, in the new-born and in the adult cat, by M. H. Schiller. The number does not increase during life (or increases very little); average 2942 in the kitten, 3035 in the cat. The calibre is increased six or eight times. - On the preceding investigation, by M. Aug. Forel. Various researches point to the stability of the nervous elements during life, and this he regards as very important for explanation of the phenomena of memory. - On the vitality of trichinæ, by M. Paul Gibier. He submitted small pieces of fresh pork with numerous trichinæ (which were much more lively when brought out of their cysts into a waterheated vessel than those of the salt meat) to a temperature of $20^{\circ}$ to $25^{\circ}$ below zero, for about two hours, and found the animals, on reheating, as lively as before.-The innervation of the osphradium of mollusks, by M. Paul Pelseneer. Like the other sensorial organs of mollusks, the osphradium proves to be innervated by the cerebral ganglion.-On the Spongeliomorpha Saportai, a new Parisian species, by M. S. Menier.

BOOKS, PAMPHLETS, and SERIALS RECEIVED.

On the Causes, Treatment, and Cure of Stammering: A. G. Bernard (Fhurchill). - A Text-book of Physiology, 5th Edition, Part $2:$ M. Foster (Macmillan).-A Contribution to the Flora of Derbyshire: Rev. W. H Painter (Bell).-Nites on the Pinks of Western Europe: F. N. Williams (West). - Watts' Dictionary of Chemistry, vol. ii.: M. M. P. Muir and $\mathbf{H}$ F. Morley (Longmans). - The Microscope in the Brewery and Malthouse: C. G. Matthews and F. E. Lott (Bemrose), - An Epitome of the Synthetic Philosophy: F. H. Collins; Preface by H. Spencer (Williams and Norgate). - Nature Stories, Myths, and Phantasies (Hamilton). - Prodromus of the -Nature Stories, Myths, and Phantasies (Hamilton). - Prodromus of the
Zoology of Victoria, Decade xviii. : F McCoy ('Trübner). - Service Che-
mistry V. B. Lewes (Whitingham) - Chemical 'Technology mistry : V. B. Lewes (Whittingham). - Chemical 'Technology ; vol. i. Fuel and its Applications: F. J. Mills and F. J. Rowan (Churchill). - The Cradle of the Aryans: G. H. Rendall (Macmillan).-Mount Vesuvius : J. L Lobley (Roper and Drowley). - Thermodynamics of the Steam-Engine: C. H. Peab dy (Macmillan) - A Manual of Forestry, vol. i. The Utility of Forests and Fundamental Principles of Sylviculture: W. Schlich (Bradbury) - Sixth Annual Report of the Bureau of Ethnology, 1884-85: J. W. Powell (Washington). - Hydrostatics for Beginners: F. W. Sanderson (Macmillan) Differential Equations: W. W. Johnson (Macmillan).-Manures and their Uses: A. B. Griffiths (Bell).-A Text-book of Physiology; vol. ii. Special Physi logy: J. G. M'Kendrick (Glasgow, Maclehose)-Problems of the Future, and Essays: S. Laing (Chapman and Hall).-Geological Record for I880-84, vol. ii. : Edited by Tupley and Sherb rn (Taylor and Francis). The Brook and its Banks: Rev. J. G. Wood (Religious Tract Society). Memoirs and Proceedings of the Manchester Literary and Philosophical Society, $4_{\text {th }}$ series, vol. ii. (Manchester). - Notes Biographiques sur J. C. Houzeau: A. Lancaster (Bruxelles). - Notes on Indian Insect Pests, vol. i. No. I (Calcutta). - Das Australische Florenelement in Europe; Dr. C. Ettingshausen (Gray) - Onderhouden Trillingen van Gespannen Draden: H. J. Oosting (Helder De Boer).-Records of the Geological Survey of New South Wales, vol. i. Part 2 (Sydney, Potter). - Internationales Archiv für Ethn graphie; Band ii. Heft 4 (Trübner).- Jahrbuch der k.k. Geologischen Reichsanstalt, Jahrg. I889. xxxix. Band, I and 2 Heft (Wien, Hölder). - The Photographic Quarterly, No. I (Hazell). Bulletin of the United States National Museum, No. 37: W. H. Dall (Washington)-Aus dem Archiv der Deutschen Seewarte, xi. Jahrg., I888 (Hamburg) - Mind September (Williams and Norgate). -Bulietin of the United S ates National Museum, No. 35: H. Edwards (Washingtun).

\section{CONTENTS}

PAGE

The Scientific Collections at South Kensington . 565

Darwinism. By Prof. E. Ray Lankester, F.R.S. . . 566

Galton's African Travels ....... 570

Our Book Shelf:-

Dibdin: "Practical Photometry"....... 572

Letters to the Editor:-

The Testing of Colour-Blindness.-Rev. J. F. Heyes ............ . 572

Mites. F. T. Mott . . . . . . . . 572

Sailing Flight of Large Birds over Land. -Dr. R.

Courtenay

Comarkable

Glaisher, F.R.S. . . . . . . . . 573

Notes ............. . . 576

Astronomical Phenomena for the Week 1889

October $\mathrm{r}_{3-19}$. . . . . . . . . . . 578

The Life.Work of a Chemist. By Sir Henry E.

Roscoe, M.P., F.R.S. . . . . . . . 578

The Physical Papers at the British Association . . 583

The Chemical Papers at the British Association . . 587

Societies and Academies .......... 588

Books, Pamphlets, and Serials Received . . . 588 